\title{
Maternal Uniparental Disomy Chromosome 14 Syndrome
}

National Cancer Institute

\section{Source}

National Cancer Institute. Maternal Uniparental Disomy Chromosome 14 Syndrome. NCI Thesaurus. Code C120409.

A cause of obesity that results from inheritance of two copies of chromosome 14 from the mother, and no copy of chromosome 14 from the father. 